\title{
الآثار الاقتصادية للتغيرات المناخية على محصول الزيتون بمحافظة مطروح
}

رجب إسماعيل مراد'،عمرو عبدالحميد رفعت`، محمد رشاد عبدالفتاحّ وأحمد أيوب عبدالعزيزء

\section{المقدمة - - مقا}

تمثل ظاهرة التغيرات المناخية تحدياً عظيماً للعالم نظراً لتسبيها في عملية تغيير النظم البيئية للأرض، وعلى الرغم

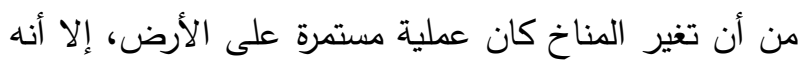

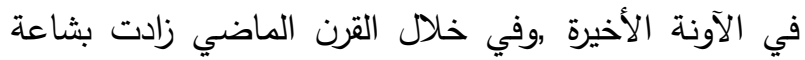
التطرفات المناخية والتي غالبا نتجت بسبب الأنشطة البشرية غير المسئولة، إن تأثير التغيرات المناخية شامل للغاية ولكن

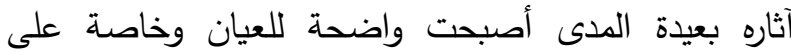
القطاع الزراعي، الذي يعتدد عليه في إنتاج الغذاء واقتصاد

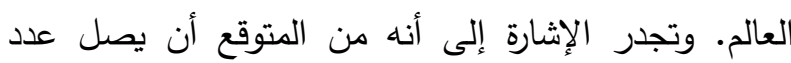

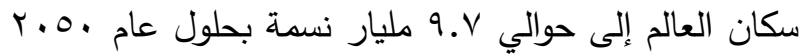

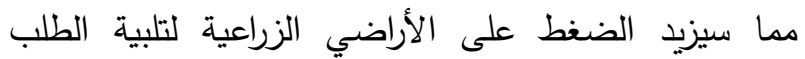
العالمي المتزايد على الغذاء المتأثر بالفعل بتأثير التغيرات

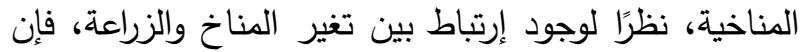
التغيرات المفاجئة في الظروف المناخية بهذه الوتيرة السريعة

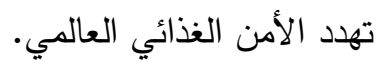

يمثل القطاع الزراعي أهمية كبيرة للاقتصـاد الصصري

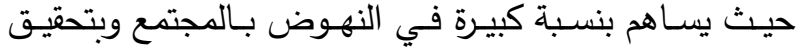
التتمية المستدامة لدا له من تأثير على الدخل المصري حيث لهي بلغت قيمة الإنتاج الزراعي المصري حوالي ل. .0 مليار جنيه (الجهاز المركزي للتعبئة العامة والإحصاء، نشرة تقدير الدخل

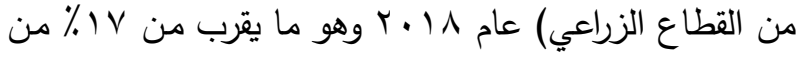

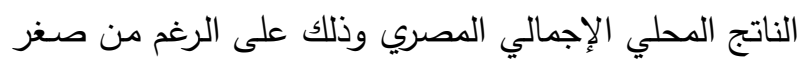
المسـاحات الزراعيـة بالنسبة لجمهوريـة مصر العربيـة حيث العيث

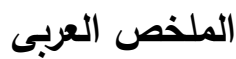

يتأثر الإنتاج الزراعي بالتغيرات المناخية وهذه التغيرات

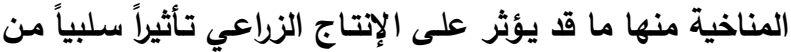
خلال نقص الإتتاجية لبعض المحاصيل الزراعية وبعض التانيات التأثيرات

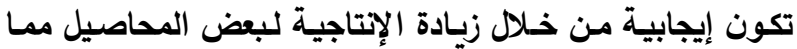

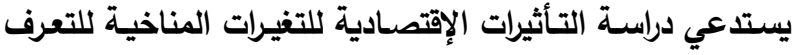
على أهم العوامـل المناخيـة التي تـؤثر على إنتـاج محصول الزيتون في محافظة مطروح. تبين مـن نتـائج تحليـل الإحـــار البسـيط لأتـر التغيـرات

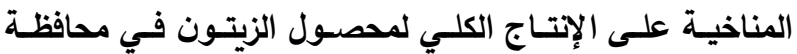

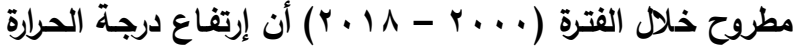
العظمى في شـهر يونيو بمقدار درجة واحدة يؤدي إلى زيـادة

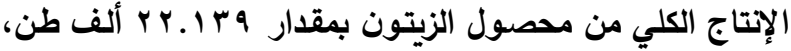
كما تبين أن إرتفاع درجة الحرارة الصغرى في شهر مايو بمان بمقدار

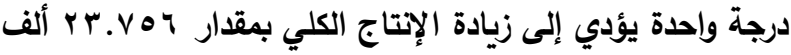

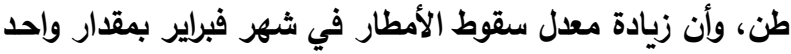

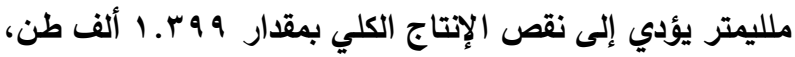

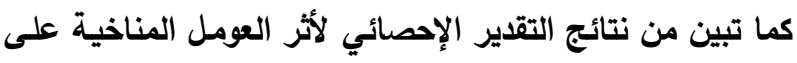

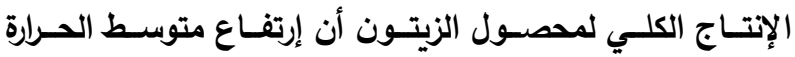

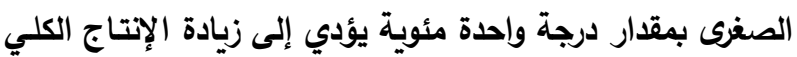

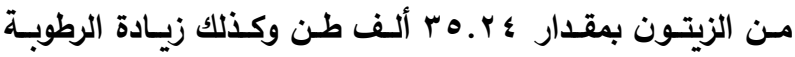

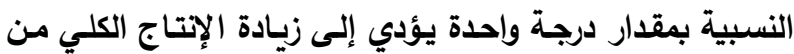

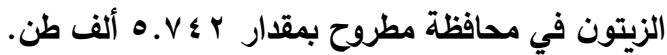
الكلمات المفتاحية: التغيرات المناخية - الزيتون - الإنتاجية - الحرارة العظى - الحرارة الصغرى - الرطوبة النسبية -

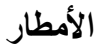


10 فوائـد صـحية وغذائيـة كثيـرة لتركيبـه الكيميائي المتميز عـن

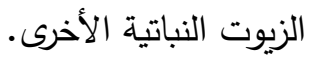

يعتبر المنـاخ هو التفاعل طويـل المدى لدرجـة الحرارة ومعدل سقوط الأمطار والرطوبة والريـاح والضوء حيث يتميزه بتأثيره على الأنظمة البيئية مثل الغابات المجودة على حواف ولف ولى

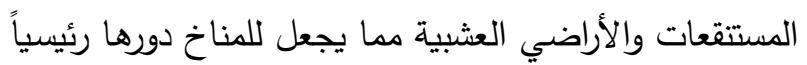

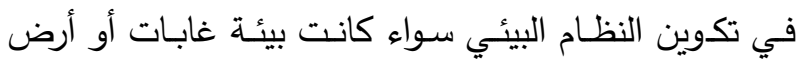
عشبية أو منـاطق صـحراوية ممـا يتوقـع أن يكـون للتغيـرات

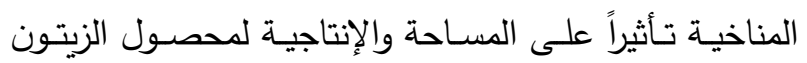
سواء كانت هذه التأثيرات سلبية أو إيجابية. مشكلة البحث: يتأثر الإنتاج الزراعي بالتغيرات المناخية التي منها ما قد

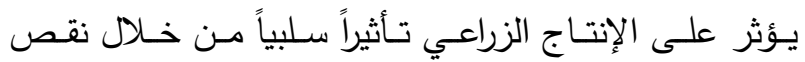
الإنتاجية لبعض المحاصيل الزراعية، وبعض التأثيرات تكون إيجابية من خلال زيادة الإنتاجية لبعض المحاصيل الزراعية بالإضـافية إلىى أن التغيـرات المناخيـة في جمهوريـة مصـر العربيـة قد تيؤدي إلى تغير في التركيب المحصـولي وتغير

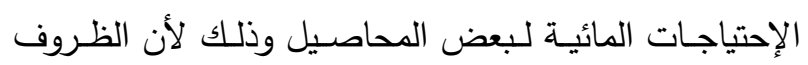

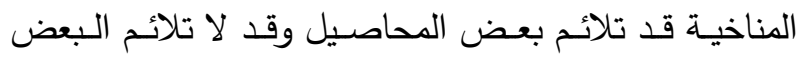
الآخر من المحاصيل وذلك حسب إحتياجات تلك المحاصيل من درجات الحرارة والرطوبـة النسبية ومعدل سقوط الأمطار وغيرها من العوامل المناخية التي تؤثرعلى الإنتاج الزراعي سواء كان أثر التغيرات المناخية إيجابي أو سلبي على إنتاج

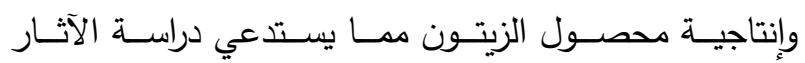

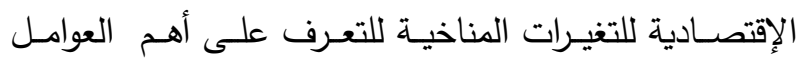
المناخية التي تؤثر على إنتاج محصول الزيتون في محافظة مطروح.
تمثل الأراضي الزراعية حوالي ج.ب \% من مساحة جمهوريـة مصر العربية البالغـة حوالي مليون كيلو متر مربع، وتظهر أهمية القطاع الزراعي في توفير فرص العمل وتثغيل العديد

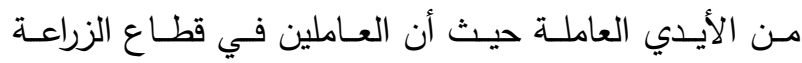
يمثلـون حـوالي \% ب مـن القـوى العاملـة فـي مصـر سـواء العاملين في الإنتاج الزراعي أو التسويق أو التصنيع. للزيتون أهمية كبيرة في مصر حيث يساهم في الناتج القومي الزراعي المصدري بالإضـافة إلى توفير المواد الخام لبعض الصناعات الغذائية حيث يزرع الزيتون في مصر إما لإسا

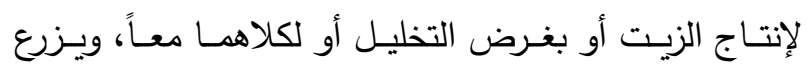
الزيتون في مصر في معظم المحافظات بصورة منفردة غالباً أو مع محاصيل أخرى فقد زادت المساحة المثمرة بالزيتون في

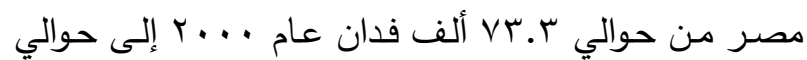

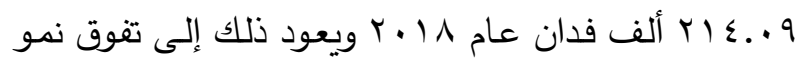
شـجرة الزيتون بمنـاطق الإستصـلاح الجديدة عن غيرهـا مـن

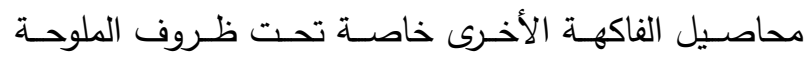
والجفاف وتباين أنواع التربة حيث أن هناك مناطق إستصـلاح

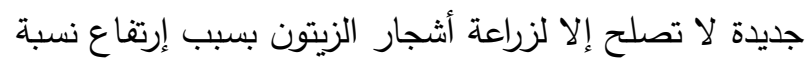

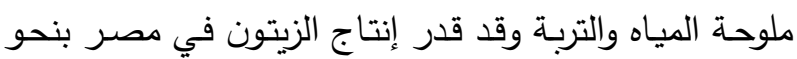

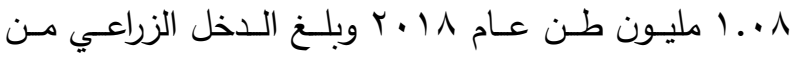
الزيتون في مصر حوالي به.0 مليار جنيه لنفس العام، كما

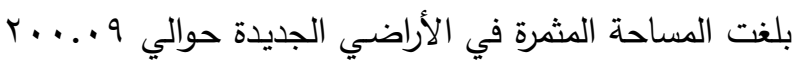

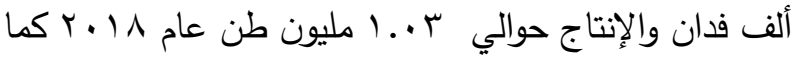

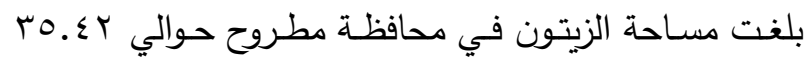
ألف فدان تمثل حوالي V.V V مـ مس مساحة الزيتون في الأراضـي الجديدة والإنتاج من الزيتون في محافظة مطروح

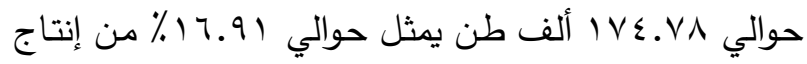
الزيتون في الأراضي الجديدة.

وتعد ثمار الزيتون ذات قيمة غذائية مرتفعة فهي غنية

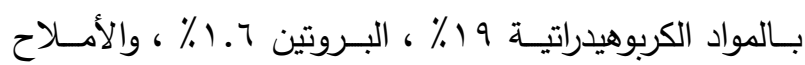
المعدنية والفيتامينات بالإضافة إلى محتواها العالي من الزيت 
r/ه رجب إسماعيل مراد،عمرو عبدالحميد رفعت واخرون.: الآثار الاقتصادية للتغيرات المناخية على محصول الزيتون بمحافظة مطروح

أولاً : المؤشرات الإتتاجية لمحصول الزيتون:

تشمل المؤشرات الإنتاجية كل من المساحة المثمرة من

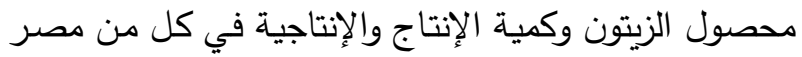

ومحافظة مطروح.

ا-تطور المساحة المثمرة لمحصول الزيتون في مصر: يتضح من جدولي (1 ، ب أن المساحة المنزرعة المثمرة

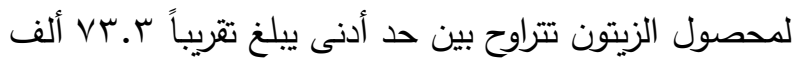

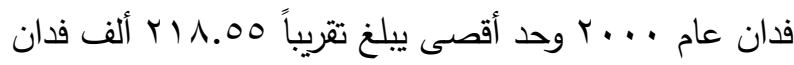

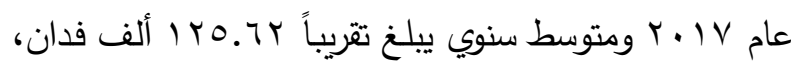

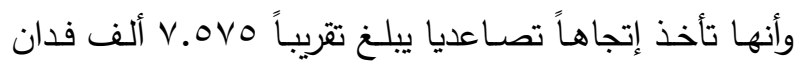

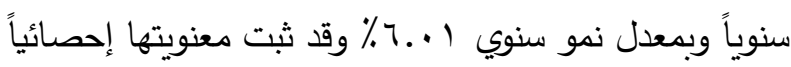

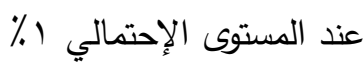

r- تطور الطاقة الإنتاجية لمحصول الزيتون في مصر:

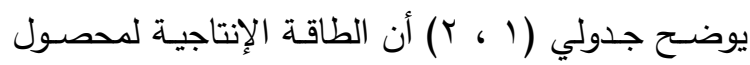

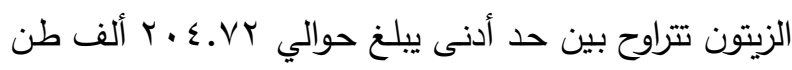

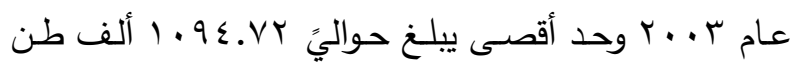

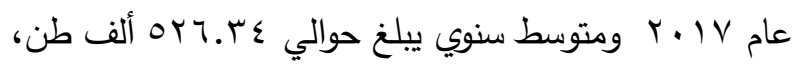

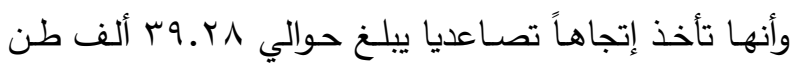

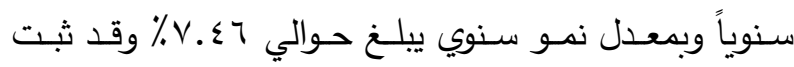

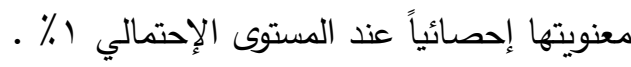
r- تطور الإتتاجية لمحصول الزيتون في مصر:

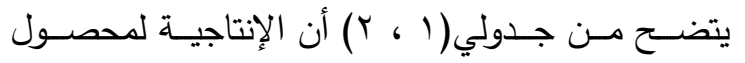

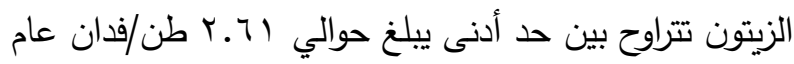

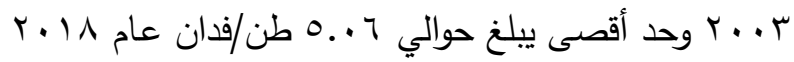

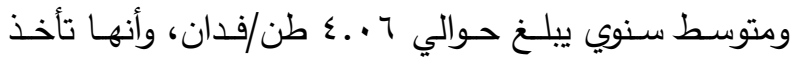

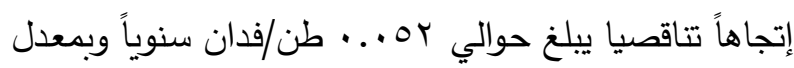

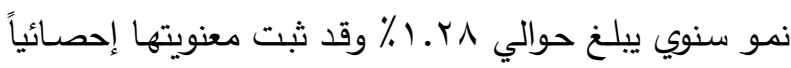

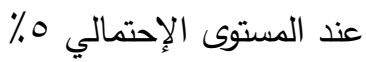

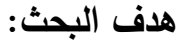

يستهدف البحث بصفة رئيسية دراسة الآثار الاقتصادية

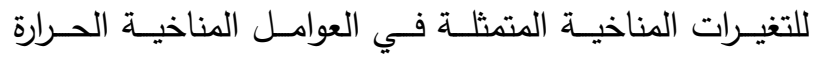

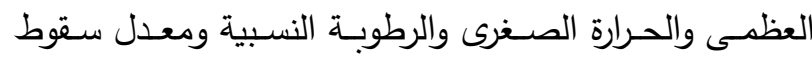

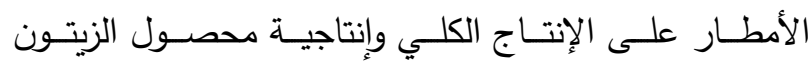

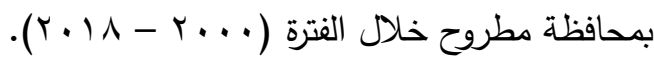

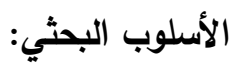

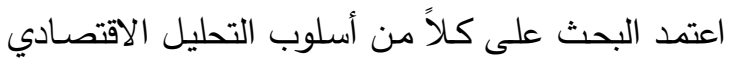
الوصفي والكمي من خـلال التوصيف الاقتصـادي اللمتغيرات

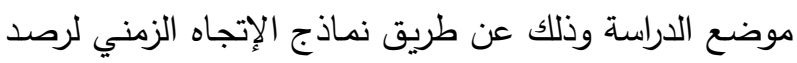
الإتجاه الزمني لكل من بعض العوامل المناخية والإنتاجيـة

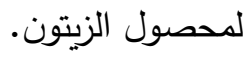

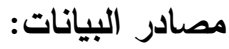

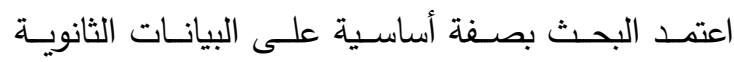
المنشورة لدى الجهات والهيئات الحكومية المحلية والدولية مثل

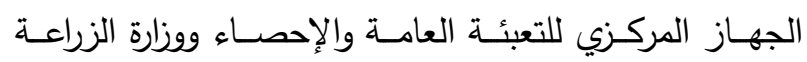

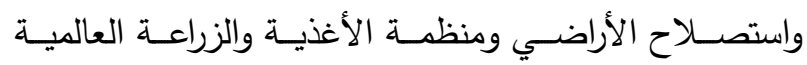

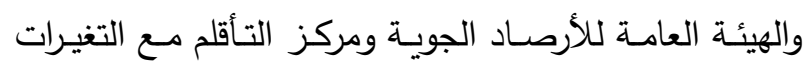

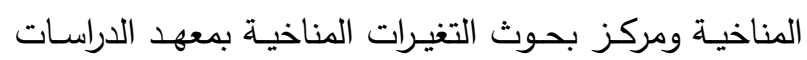
العليا والبحوث جامعة الأسكندرية.

\section{النتائج البحثية}

استهدف البحث تقدير تطور كل من الدخل الزراعي

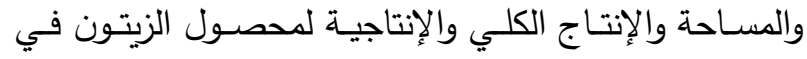

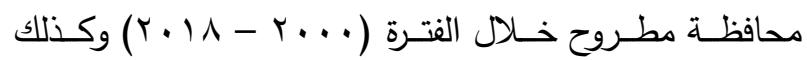
تقدير الآثار الاقتصادية للتغيرات المناخية المتمثلة في الحرارة العظمى والحرارة الصغرى والرطوبـة ومعدل سقوط الأمطار على الإنتاج الكلي والإنتاجية لمحصول الزيتون . 
يبلغ حوالي 99.rV ألف فدان، وأنها تأخذ إتجاهاً تصاعديا

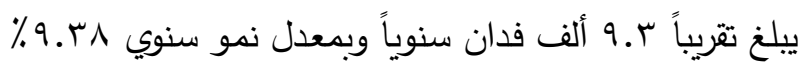

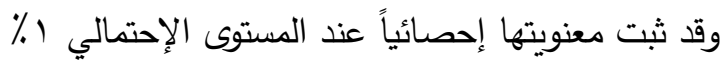

؛ -تطور المساحة المثمرة لمحصول الزيتون في الأراضي

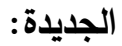

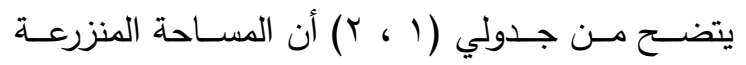

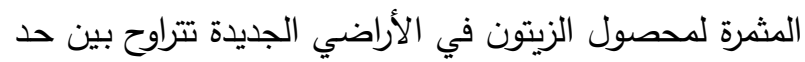

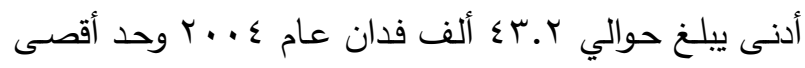

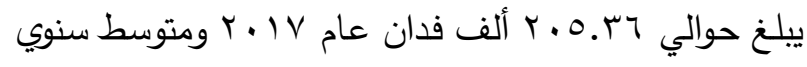

جدول 1. تطور المساحة المثمرة والإتتاج والإنتاجية لمحصول الزيتون في مصر والأراضي الجديدة خلال الفترة (... ب-

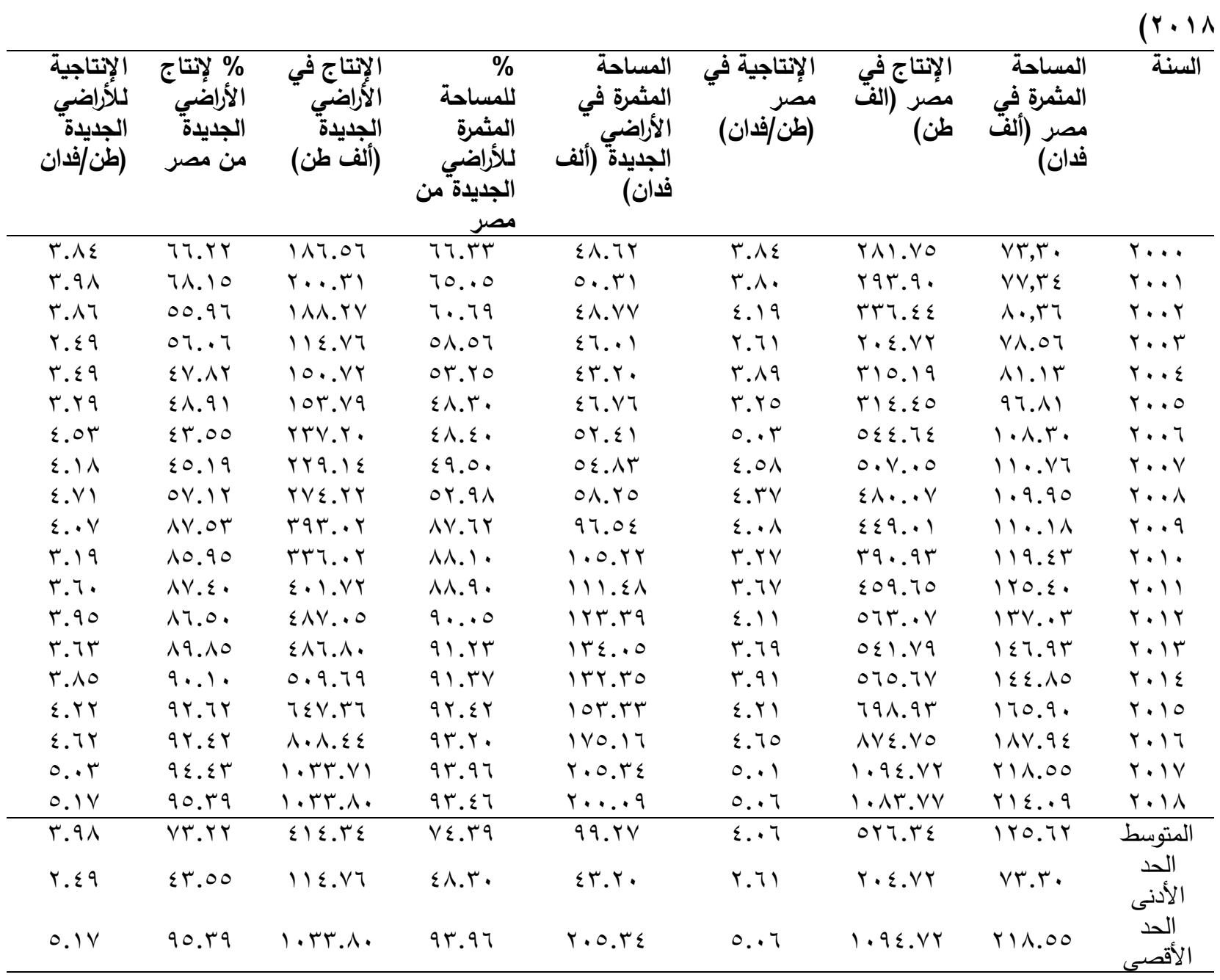

المصدر :. وزارة الزراعة واستصلاح الأراضي، قطاع الثئون الاقتصادية، نشرة الاقتصاد الزراعي، أعداد متثرقة 
010 رجب إسماعيل مراد،عمرو عبدالحميد رفعت واخرون.: الآثار الاقتصادية للتغيرات المناخية على محصول الزيتون بمحافظة مطروح

جدول r. معادلات الإتجاه الزمني لتطور المساحة المثمرة والإنتاج والإنتاجية في مصر ومطروح لمحصول الزيتون خـلال

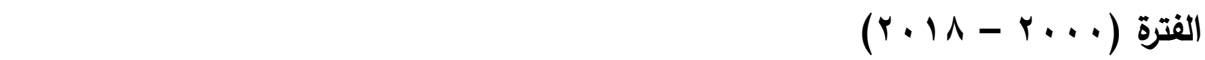

\begin{tabular}{|c|c|c|c|c|}
\hline rj & ت & ف & المعادلة & المتغير التابع \\
\hline .9 .7 & "Ir.Vq & "17r.70 & ص = & فالم.الــاحة المثـرة في مصــر (ألف \\
\hline.$V \circ V$ & "*V.rV & $* *$ or.A $\leqslant V$ & ص= § & الإنتاج فى مصر (ألف طن) \\
\hline..$T \cdot V$ & "Y. Y. & $" \varepsilon . \leqslant 0$ & ص= & الإنتاجية فى مصر (طن/فدان) \\
\hline. .19 & $" * 11.14$ & $"$ "I rq.VA & ص & المســاحة ألمثــرة فـي الأراضـــي \\
\hline$\cdot . \wedge / V$ & ${ }^{* *} \wedge . \vee 1$ & 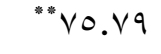 & ص= - - & الإنتاج في الأراضي الجديدة (ألف \\
\hline.$r V \varepsilon$ & " "Y.oro & 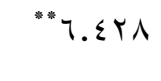 & 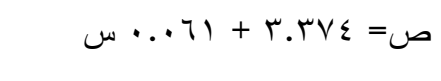 & فـي الأراضــي الجديـدة \\
\hline$\cdot .9 \cdot 1$ & "*I T. $\varepsilon \varepsilon$ & $* * 105.7 r$ & ص & فدان) المساحة المثرة في مطروح (ألف \\
\hline 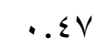 & 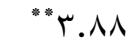 & " & ص= 10 & الإنتاج فى مطروح (ألف طن) \\
\hline$\ldots 1 \pi$ & $\therefore \leqslant 70$ &..$Y 17$ & ص= & الإنتاجية في مطروح (طن/فدان) \\
\hline
\end{tabular}

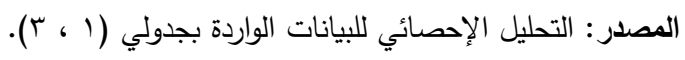

طن/فدان سنوياً وبمعدل نمو سنوي يبلغ حوالي rه. 1 ٪ وقد

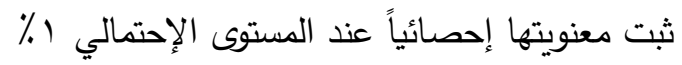
V-تطور المساحة المثمرة لمحصول الزيتون في مطروح: تبين من جدولي (Y ، r) أن المساحة المنزرعة المثمرة لمحصول الزيتون في مطروح تتراوح بين حد أدنى يبلغ تقريباً

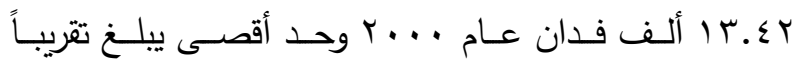

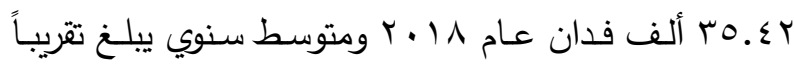
r. Y. Y ألف فدان، وأنها تأخذ إتجاهـاً تصـاعديا يبلغ تقريباً

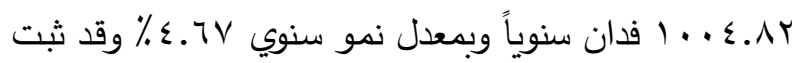

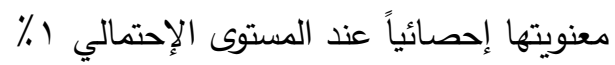

\section{1-تطور الطاقة الإنتاجية لمحصول الزيتون في مطروح :}

تبين من جدولي (r ، r) أن الطاقة الإنتاجية لمحصول

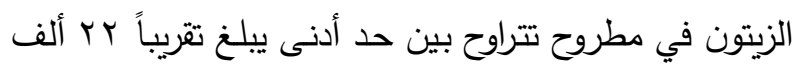

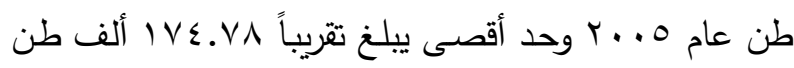

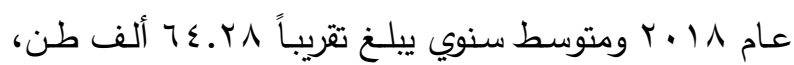

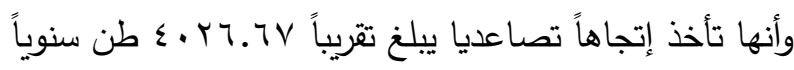

ه-تطور الطاقة الإنتاجية لمحصول الزيتون في الأراضسي الجديدة :

تبين من جدولي (Y ، r) أن الطاقة الإنتاجية لمحصول الزيتون في الأراضي الجديدة تتراوح بين حد أدنى يبلغ حوالي

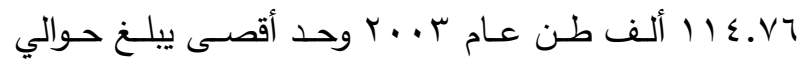

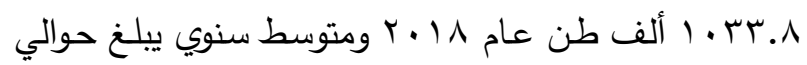
ع ا.ء (اء ألف طن، وأنها تأخذ إتجاهاً تصاعديا يبلغ حوالي

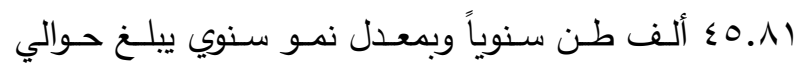
1 ا 1 \% وقد ثبت معنويتها إحصائياً عند المستوى الإحتمالي

צ-تطــور الإنتاجيـة لمحصـول الزيتـون فـي الأراضــي الجديدة:

تبين من جدولي (Y ، r) أن الإنتاجية لمحصول الزيتون

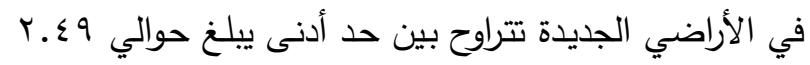

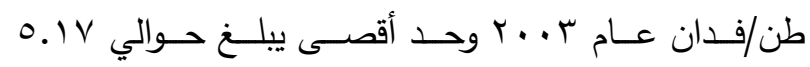

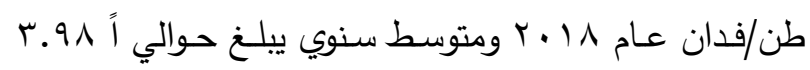

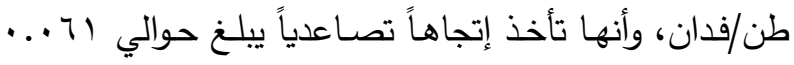




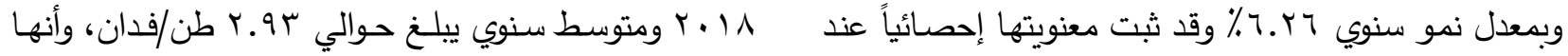

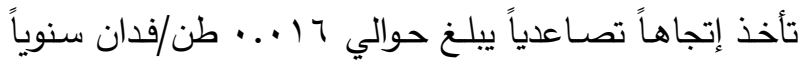
وبمعدل نمو سنوي يبلغ حوالي 00. • ٪ ولم تثبت معنويتها

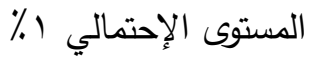
إحصائياً. 9-تطور الإتتاجية لمحصول الزيتون في مطروح : تبين من جدولي (r ، ؟r) أن الإنتاجية لمحصول الزيتون

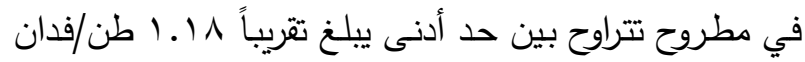

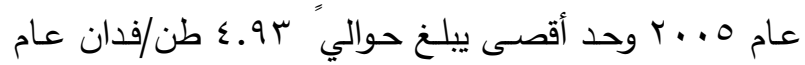
جدول r. تطور المساحة المثمة والإنتاج والإتتاجية لمحصول الزيتون في الأراضي الجديدة ومحافظة مطروح خلال الفترة

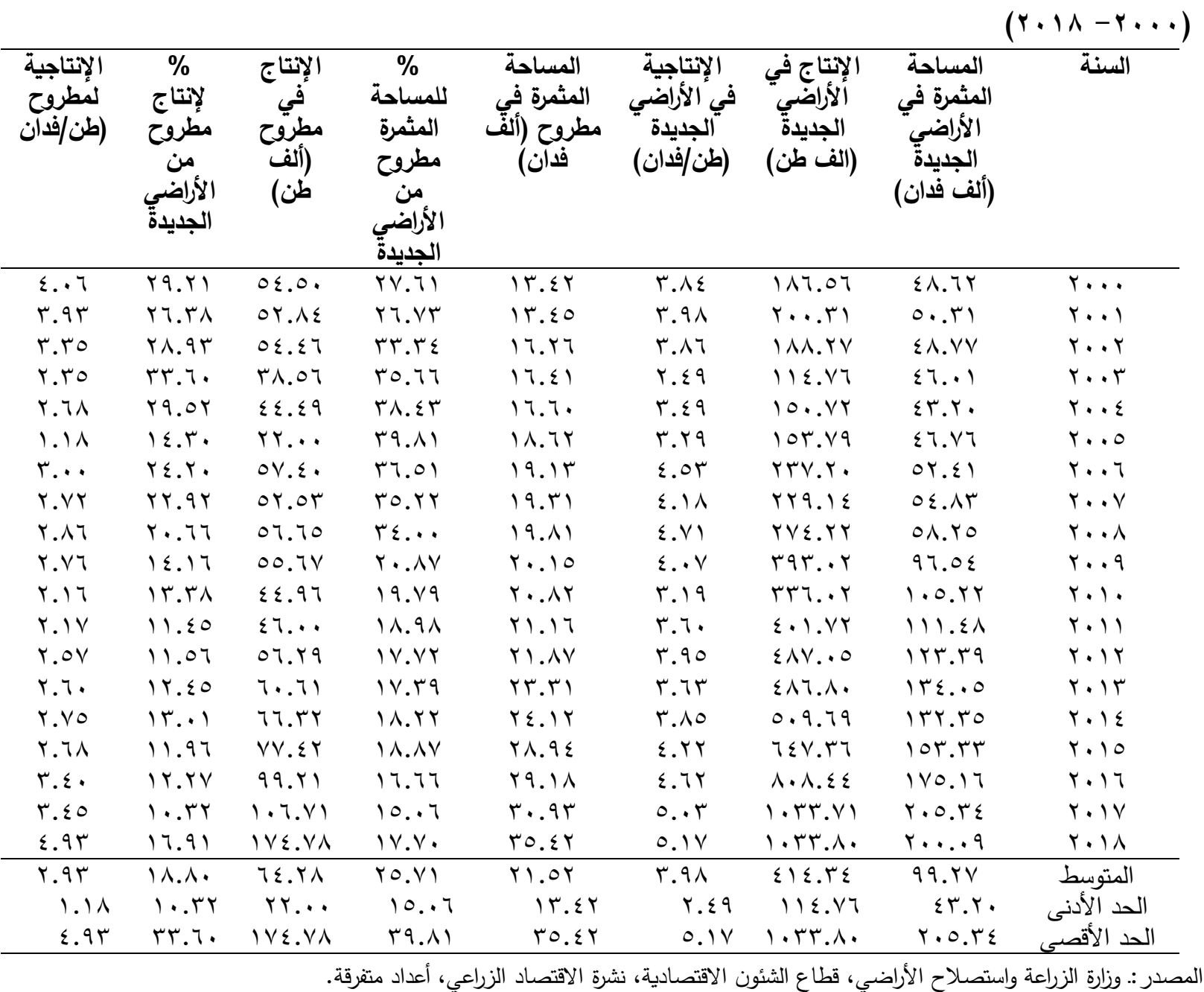


ONV رجب إسماعيل مراد،عمرو عبدالحميد رفعت واخرون.: الآثار الاقتصادية للتغيرات المناخية على محصول الزيتون بمحافظة مطروح

الحرارة المتوسطة تأخذ إتجاهاً تصاعديا يبلغ تقربباً 01 . . . ثانياً: العوامل المناخية: درجة مئوية وبزيادة سنوية تقدر و ب . . • وقد ثبت معنويتها

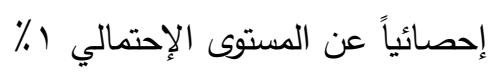
ب - برجة الحرارة العظمى تبـين مـن جـدولي (ع - 0 0) أن متوســـ درجــة الحـرارة

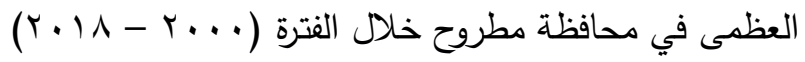

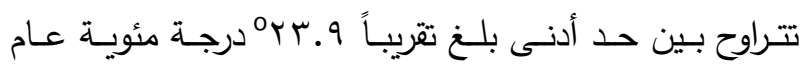

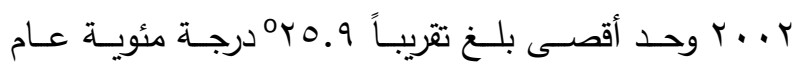

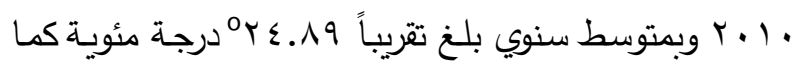

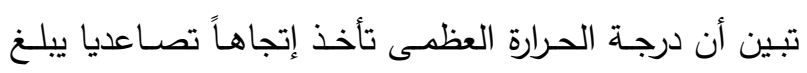

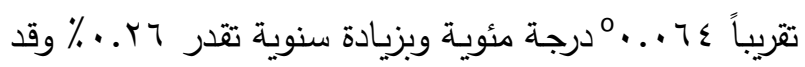

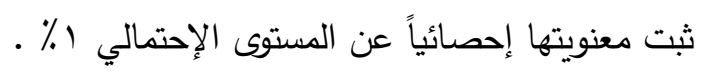

يكـون للعوامـل المناخيـة تـأثيراً هامـاً على القطـاع

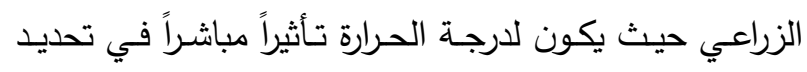

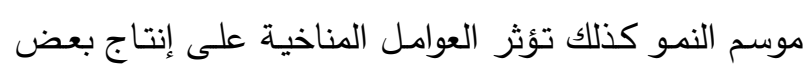

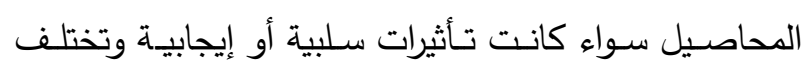
بإختلاف قدرة بعض المحاصسيل على تحمل التفـاوت في درجات الحرارة والأمطار . -

تبين مـن جدولي (ع - 0) أن درجـة الحرارة المتوسطة

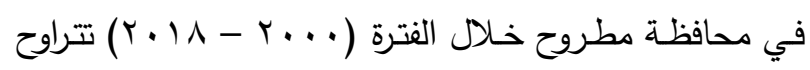

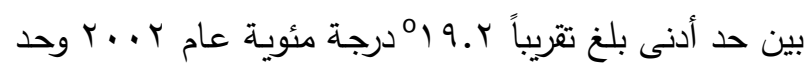

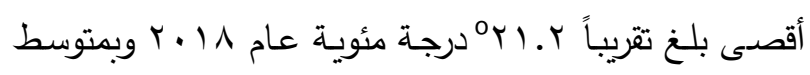

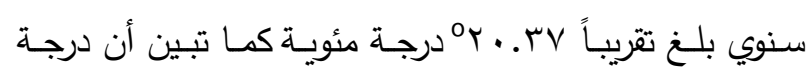

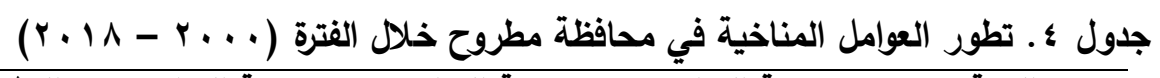

\begin{tabular}{|c|c|c|c|c|c|}
\hline الأمطار (ملم) & الرطوبة النسبية & دالصة الحرارة & داجة الحرارة & لدرجة الحرارة & السنة \\
\hline 194.40 & 79 & 10.9 & $T \leqslant . Y$ & $r . .1$ & $r \ldots$ \\
\hline $9 \wedge . r$ & 7ד. & 10.7 & ro & $r \cdot . \Sigma$ & $r \ldots l$ \\
\hline $1 \leqslant \Gamma . \varepsilon$ & 71.7 & $1 \leq .7$ & rT.q & 19.5 & $r \ldots r$ \\
\hline 17.04 & 7ד.ร & 10.7 & $r \varepsilon . \wedge$ & $r . . r$ & $r \ldots r$ \\
\hline 94.91 & $7 r .7$ & 10.7 & $r \leqslant .7$ & $r \cdot . l$ & r.. $\varepsilon$ \\
\hline $1 \leq \Psi . \wedge$ & $7 \wedge .7$ & $1 \varepsilon . \wedge$ & $r \varepsilon . r$ & 19.0 & $r . .0$ \\
\hline $11 \leq .00$ & 70.7 & $10 . V$ & $r \leqslant .0$ & $r \cdot . l$ & $r \ldots T$ \\
\hline אוונזי & $7 V .0$ & 10.1 & $r \leqslant .0$ & $r \cdot . r$ & $r \ldots v$ \\
\hline $1 T V .17$ & $70 . \mathrm{V}$ & 17.1 & YO. & $Y . . V$ & $r \ldots \Lambda$ \\
\hline 1.9 .0 & ת.זי & 10.1 & $r \varepsilon . \wedge$ & $r \cdot . \Sigma$ & $r \ldots q$ \\
\hline AV.IT & וז. & 17.0 & ro.9 & YI.l & r.. . \\
\hline $110 . V Y$ & 77.1 & 10.7 & T乏.乏 & $r . . l$ & $r .11$ \\
\hline $1.7 .7 \mathrm{~V}$ & $T V . \varepsilon$ & $17 . r$ & ro & $r . . T$ & $r .1 r$ \\
\hline $1 Y . . r q$ & $7 V .7$ & 17.1 & ro & $r \cdot .0$ & $r .1 T$ \\
\hline $7 . .97$ & $T \Lambda . Y$ & 17.1 & ro.0 & $r \cdot . V$ & r. I $\leq$ \\
\hline А५. rV & 71.0 & 10.1 & YO. & $r \cdot . \Sigma$ & $r .10$ \\
\hline 94.91 & 7. & $17 . V$ & ro.V & r.. & $r .17$ \\
\hline 117.10 & $7 V .0$ & 17.1 & $r \varepsilon . \wedge$ & $r \cdot . \Sigma$ & Y.I \\
\hline IYA.70 & 71.7 & IV & ro.V & Y.. & $r \cdot 11$ \\
\hline $1 Y 1.70$ & 77.79 & $10.1 \mathrm{~V}$ & $r \leq . \wedge 9$ & $r . . r v$ & المتوسط \\
\hline $7 . .97$ & TY.T & $1 \varepsilon .7$ & Tr.9 & 19.5 & الحد الأدنى \\
\hline או.וזי & 79 & IV & ro.9 & r..r & الحد الأقصى \\
\hline
\end{tabular}

المصدر : 1- الجهاز المركزي للتعبئة العامة والإحصاء، النشرة السنوية للجغرافيا والمناخ، أعداد متفرقة.

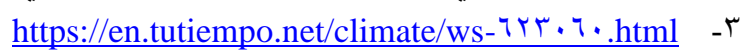




\begin{tabular}{|c|c|c|c|c|}
\hline r & $ت$ & ف & 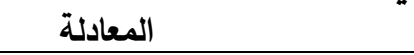 & 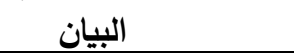 \\
\hline.$\leqslant Y O$ & $r .0 \leq 7$ & "I T.OVT & 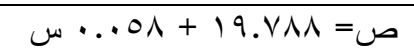 & درجة الحرارة المتوسطة \\
\hline . & "4.00 & $" *$ "I T.TIr & ص & درجة الحرارة العظمى \\
\hline.$\varepsilon 7 r$ & " & $" * 1 \leq .09 \leq$ & ص= & درجة الحرارة الصغرى \\
\hline$\ldots .1 \mathrm{~V}$ & $.0 \leqslant 1$ & r & ص= س & الرطوبة النسبية \\
\hline $.1 \times 9$ & $1.019-$ & r.oro & ص = & معدل سقوط الأمطار \\
\hline
\end{tabular}

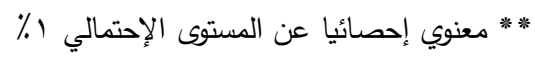

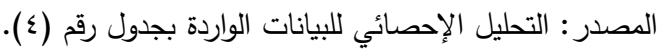

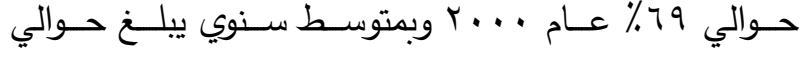

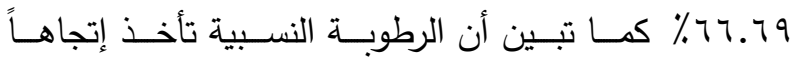
تصـاعديا يبلغ حوالي هـ ـ . . ٪ وبزيـادة سنوية تقدر بحوالي V . . . . . ولم تثبت معنويتها إحصائياً.

צ-معدل سقوط الأمطار :

تبين من جدولي (ع - 0) أن معدل سقوط الأمطار في

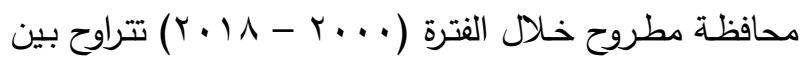

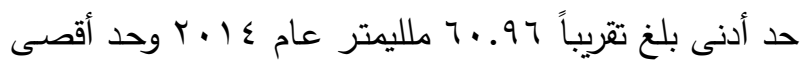

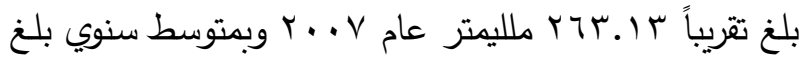
تقريباً 1 M. 10. ملليمتر كما تبين أن معدل سقوط الأمطار

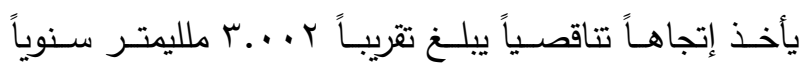
وبمعدل تتاقص سنوي سنوية يقدر بr.Y \% ولم تثبت معنويتها إحصائياً

ثالثاً: آثار التغيرات المناخية على محصول الزيتون في

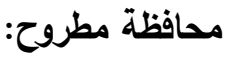
يتتاول هذا الجزء أثر التغيرات في العوامل المناخية على كلا مـن الإنتاج والإنتاجيـة لمحصـول الزيتون في محافظـة

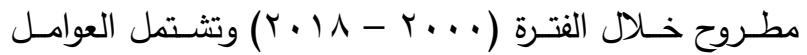
المناخيـة على المتوسط الثـهري لكل مـن الحـرارة العظمى مهى والصـغرى والرطوبـة النسبية خـلال فترة المحصـول من العـام بالإضـافة إلى معدل سقوط الأمطار الثهري وإجمالي معدل

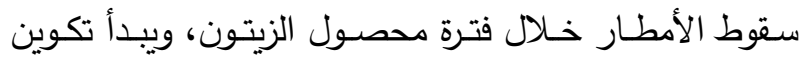
البراعم لأثجار الزيتون بداية من شهر ديسمبر من كل عام يليهـا الإزهـار والعقــ والإثــار خـلال شـهور ينـاير وفبرايـر

\section{r-درجة الحرارة الصغرى :-}

تبـين مـن جـدولي (ع - 0 0) أن متوسـطـ درجـة الحـرارة

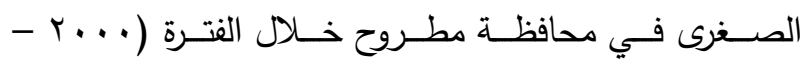

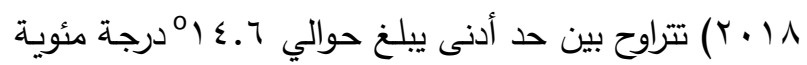

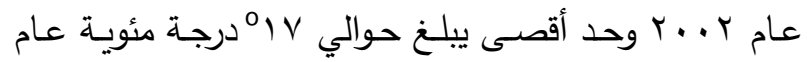

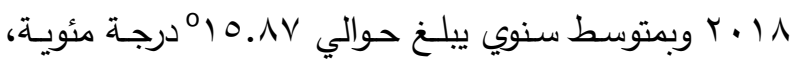
كما تبين أن درجـة الحرارة الصـغرى تأخذ إتجاهـاً تصـاعديا

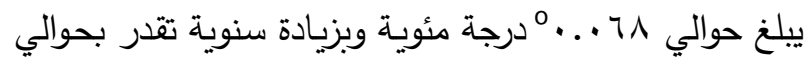
זء. . . وقد ثبت معنويتها إحصائياً عن المستوى الإحتمالي . $\%$

ع -درجة الحرارة الصغرى :

تبـين مـن جدولي (ع - 0) أن متوســ درجـة الحـرارة

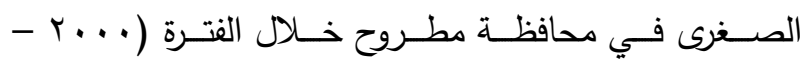

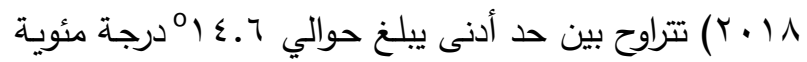

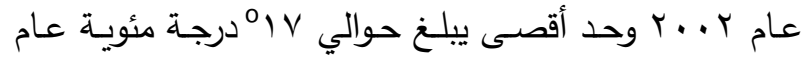

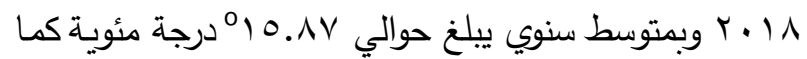

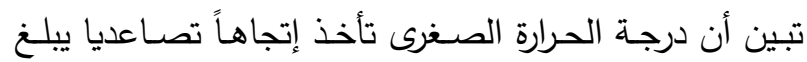

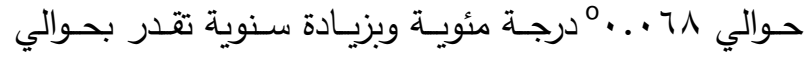
זء. . . وقد ثبت معنويتها إحصائياً عن المستوى الإحتمالي

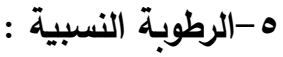

تبـين مـن جـدولي (ع - 0) أن الرطوبـة النسـبية فـي

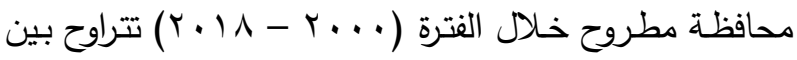

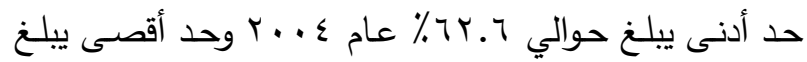


9 هo رجب إسماعيل مراد،عمرو عبدالحميد رفعت واخرون.: الآثار الاقتصادية للتغيرات المناخية على محصول الزيتون بمحافظة مطروح ومارس حتى النضـ في شهر يونيو لذلك تعد الفترة من شهر درجـة الحرارة العظمى في شهر يونيو بمقدار درجـة واحدة ديسمبر حتى شهر يونيو هي الشهور الأكثر تأثيراً على إنتاج يؤدي إلى زيادة الإنتاج الكلي من محصول الزيتون بمقدار

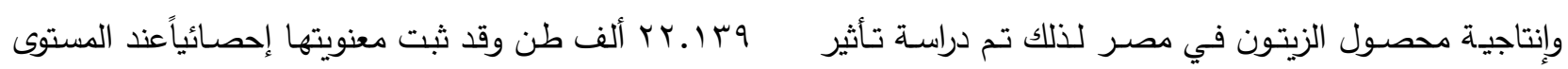
الإحتمالي ٪ ٪، علماً بأن متوسط الحرارة العظمى لشهر يونيو

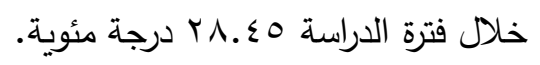
كما تبين من نتائج تحليل الإنحدار البسيط لأثر الحرارة العظمى على إنتاجية محصول الزيتون بمحافظة مطروح في

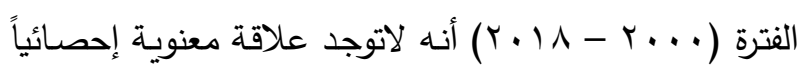
بين درجة الحرارة العظمى والإنتاجية لمحصـول الزيتون في

محافظة مطروح.

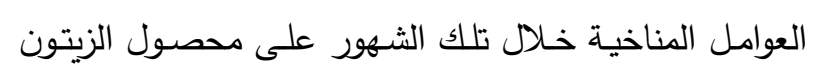
من كل موسم. - - قياس أثر الحرارة العظمى على محصول الزيتون : تبين من نتائج تحليل الإنحدار البسيط وشكل رقم (1) لأثر الحرارة العظمى على الإنتاج الكلي لمحصول الزيتون في

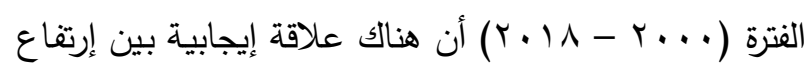
متوسط درجـة الحـرارة العظمى خـلال شـهر يونيو والإنتـاج

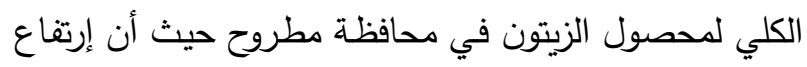

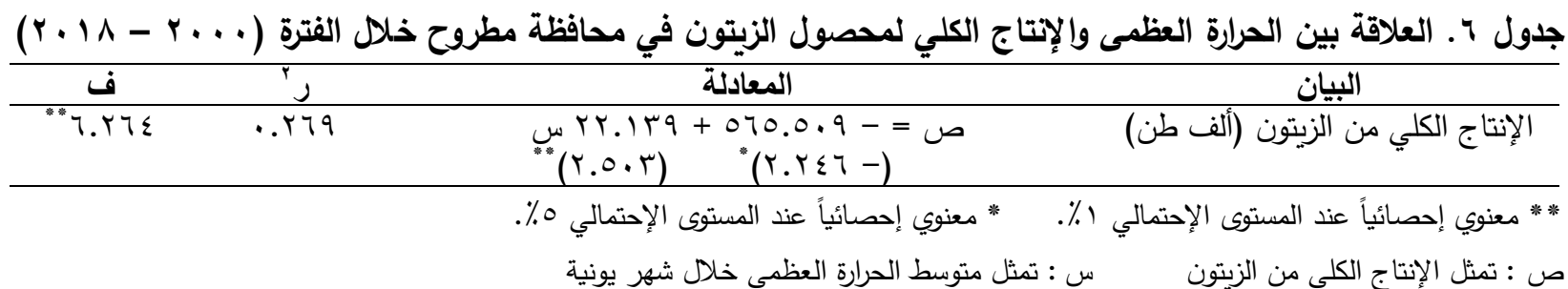

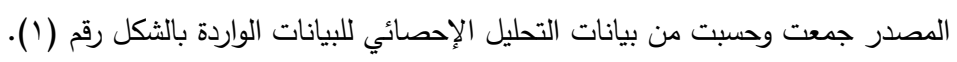

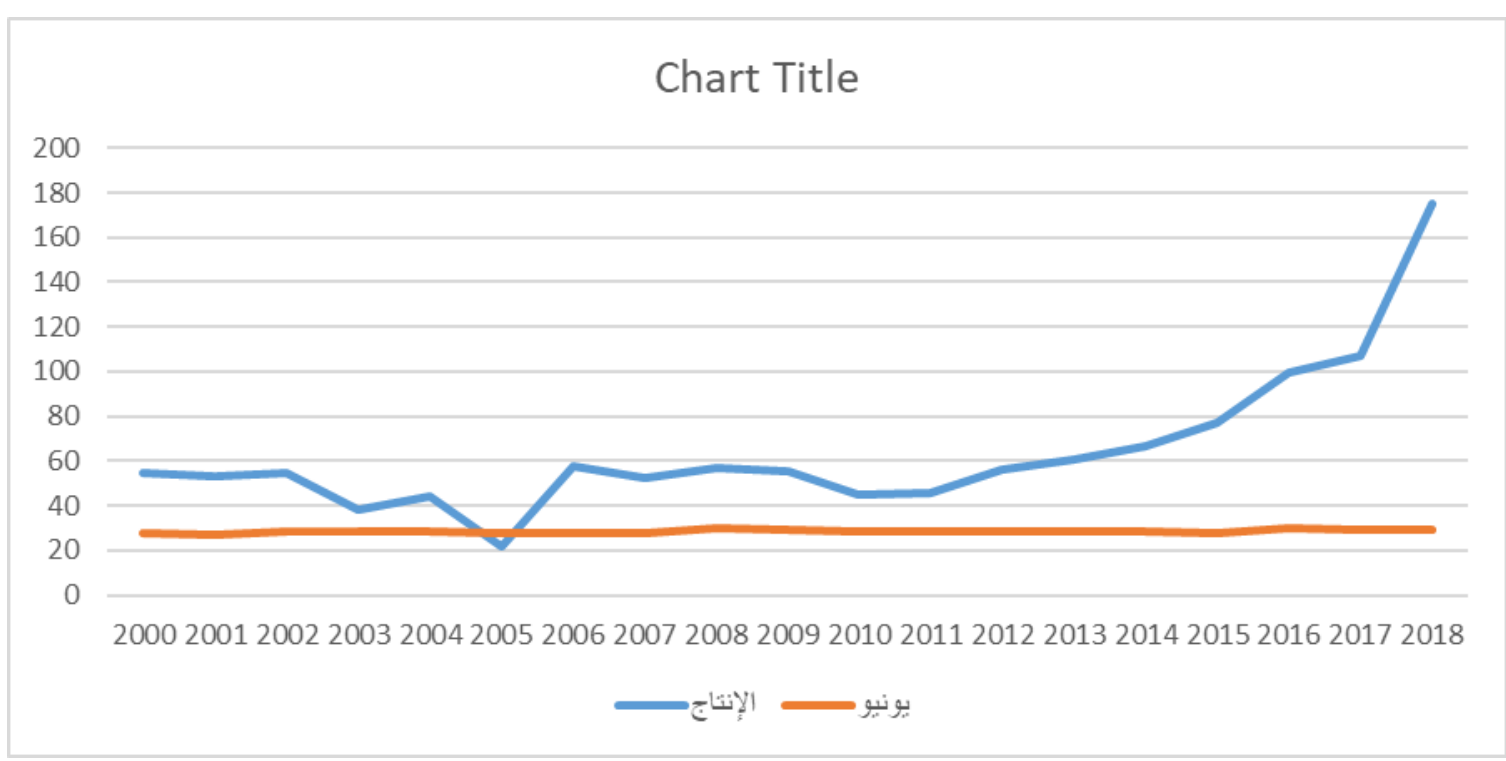

شكل رقم 1. إتجاهات درجات الحرارة العظى لشهر يونيو والإنتاج الكلي لمحصول الزيتون في محافظة مطروح خـلال الفترة $(r \cdot 1 \wedge-r \cdot \cdots)$ المصدر : الجهاز المركزي للتعبئة العامة والإحصاء، النشرة السنوية للجغرافيا والمناخ، أعداد متفرقة. 
ع- قيـاس أثـر معـدل سـقوط الأمطــار علـى محصــول

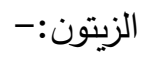

تبين من نتائج تحليل الإنحدار البسيط وشكل رقم (r) لتحليـل الإنحدار المتعـد لأثر معدل سقوط الأمطـار على العى الإنتاج الكلي لمحصول الزيتون في محافظـة مطروح خـلال

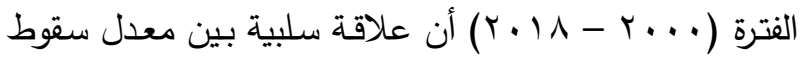
الأمطار خلال شهر فبراير والإنتاج الكلي لمحصول الزيتون في محافظة مطروح حيث أن زيادة معدل سقوط الأمطار في شـهر فبراير بمقدار واحد ملليمتر يؤدي إلى نقص الإنتاج

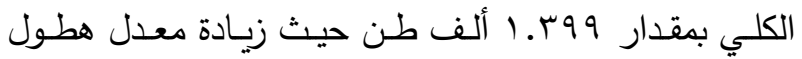
الأمطار والرطوبة النسبية يؤدي إلى عدم إتمام عملية التلقيح

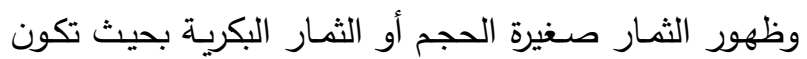
الثمار صغيرة الحجم مستديرة خالية من الجنين(Y) وقد ثبت

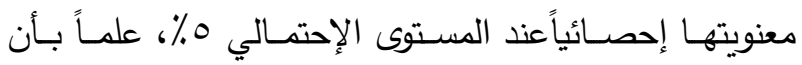
متوسط معدل سقوط الأمطار لشهر فبراير خلال فترة الدراسة

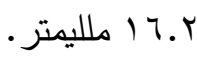

كما تبين من نتائج تحليل الإنحدار البسيط لأثر معدل سقوط الأمطار على إنتاجية محصول الزيتون في محافظة

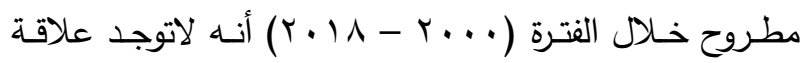
معنويـة إحصــائياً بـين معـدل سـقوط الأمطـار والإنتاجيــة لمحصول الزيتون في محافظة مطروح.

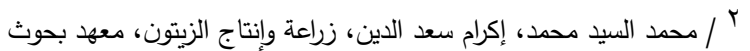

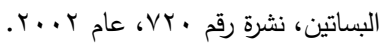

r - قياس أثر الحرارة الصغرى على محصول الزيتون : تبين من نتائج تحليل الإنحدار البسيط وشكل رقم (Y) لأثر الحرارة الصغرى على الإنتاج الكلي لمحصول الزيتون

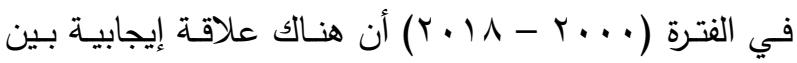

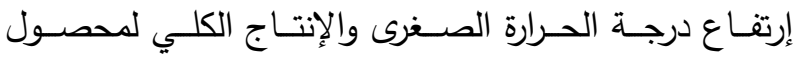
الزيتون في محافظة مطروح حيث أن إرتفاع درجـة الحرارة الصغرى في شهر مايو بمقدار درجة واحدة يؤدي إلى زيادة

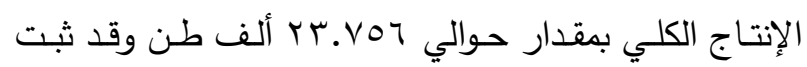

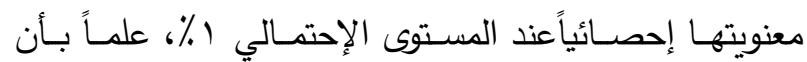
متوسط الحرارة الصـغرى لشهر مـايو خـلال فترة الدراسـة هو الإس

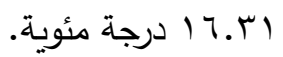

كما تبين من نتائج تحليل الإنحدار البسيط لأثر الحرارة

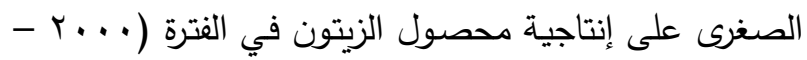

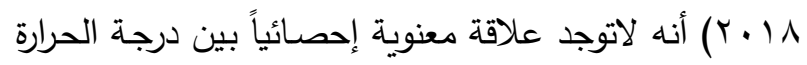
الصغرى والإنتاجية لمحصول الزيتون في محافظة مطروح. r- قياس أثر الرطوبة النسبية على محصول الزيتون : تبين من نتائج تحليل الإنحدار البسيط لأثر الرطوبـة

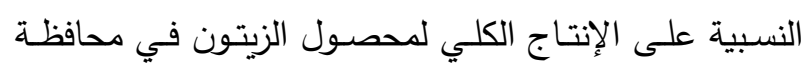

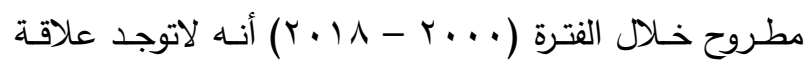
بين إرتقاع الرطوبـة النسبية والإنتاج الكلي لمحصول الزيتون في محافظة مطروح.

كما تبين من نتائج تحليل الإنحدار البسيط لأثر الرطوبة النسبية على إنتاجية محصول الزيتون في محافظة مطروح

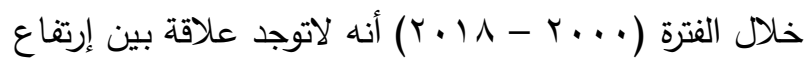
الرطوبـة النسبية والإنتاجيـة لمحصـول الزيتـون في محافظـة مطروح. 
اهوه رجب إسماعيل مراد،عمرو عبدالحميد رفعت واخرون.: الآثار الاقتصادية للتغيرات المناخية على محصول الزيتون بمحافظة مطروح

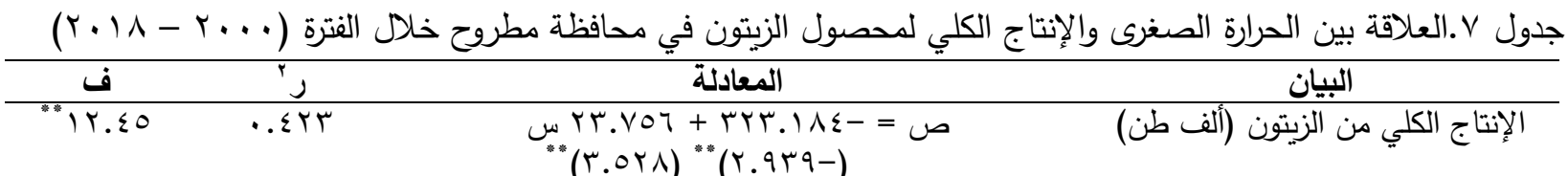

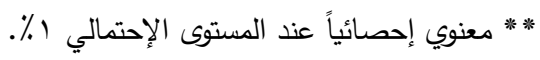

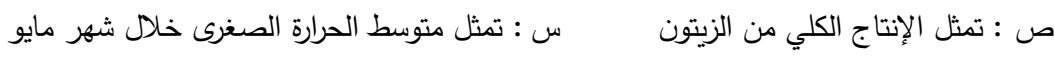

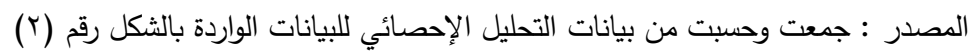

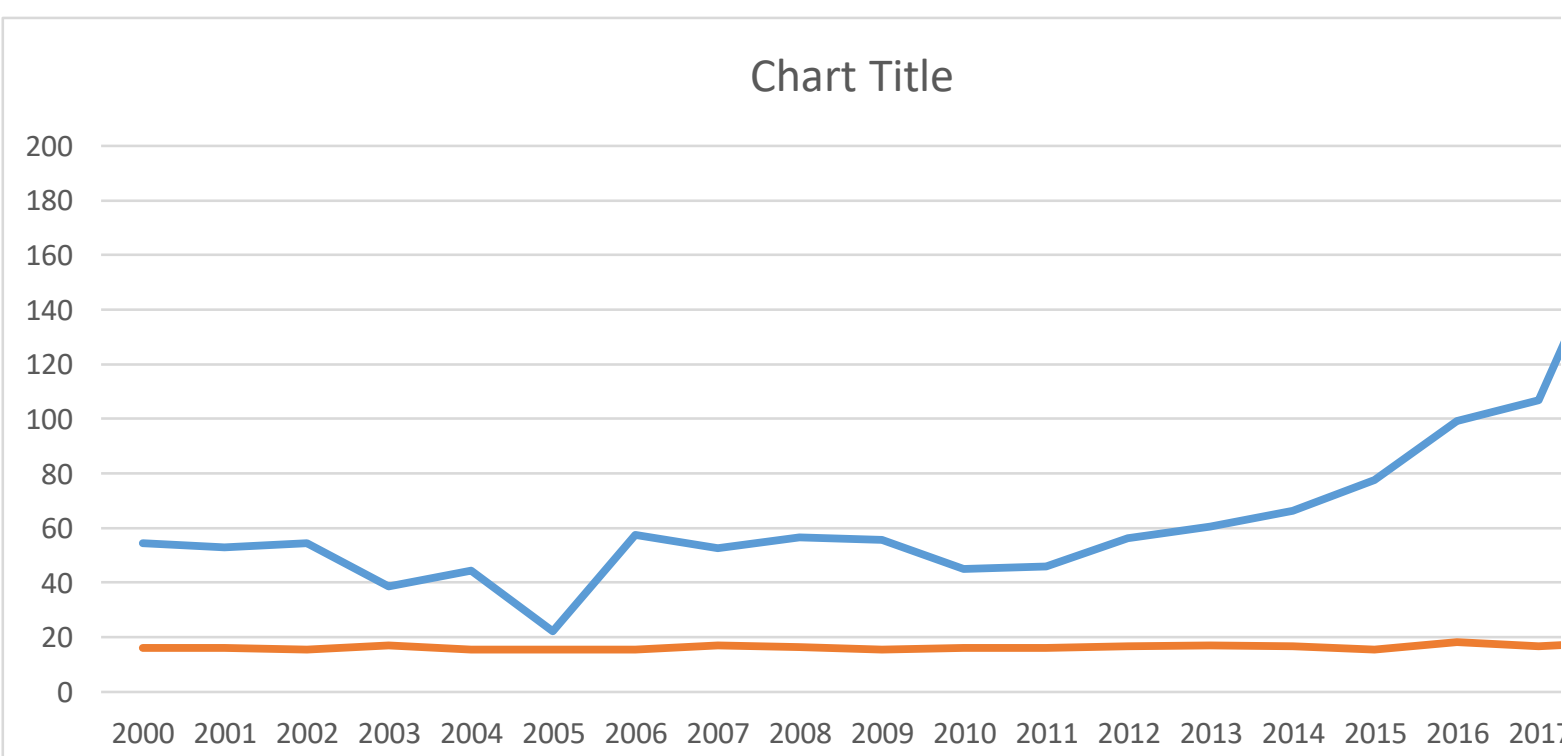

شكل رقم r. إتجاهات درجات الحرارة الصغرى لشهر مايو والإنتاج الكلي لمحصول الزيتون في محافظة مطروح خلال الفترة $(r \cdot 1 \wedge-r \cdots)$ المصدر : الجهاز المركزي للتعبئة العامة والإحصاء، النشرة السنوية للجغرافيا والمناخ، أعداد متفرقة.

جدول ^. العلاقة بين معدل سقوط الأمطار والإنتاج الكلي لمحصول الزيتون في محافظة مطروح خلال الفترة (.... . . . .

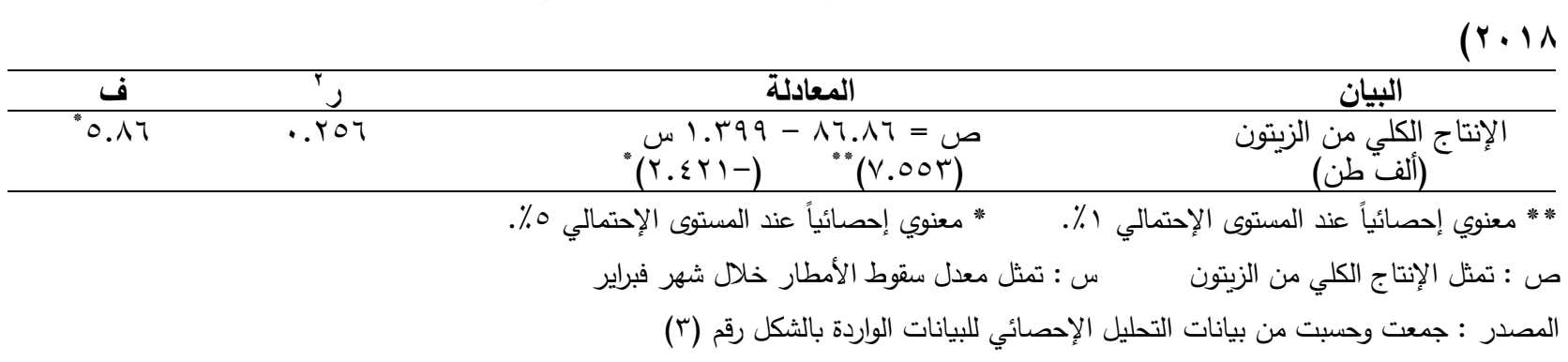




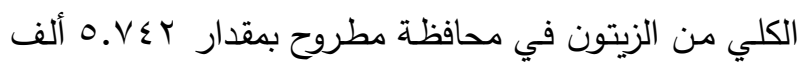

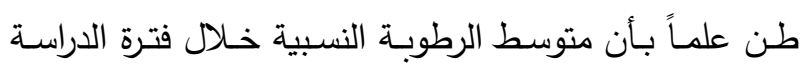

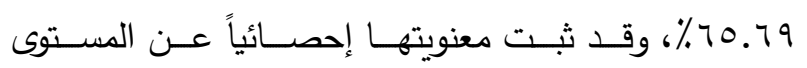

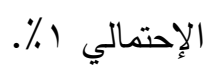

كمـا تبـين مـن نتائج التقدير الإحصـائي لأثر العومـل

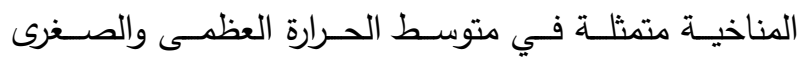
والرطوبة النسبية وإجمالي معدل سقوط الأمطار على إنتاجية

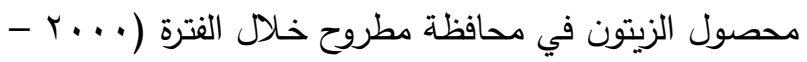

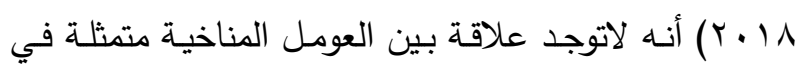
متوسط الحرارة العظمى والصغرى والرطوبـة النسبية وإجمالي

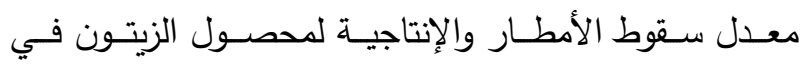
محافظة مطروح.
0- قياس تأثير العوامل المناخية على محصول الزيتون : تبين من نتائج تحليل الإنحدار البسيط وشكل رقم (ع) نتائج التقدير الإحصـائي لأثر العومـل المناخيـة متمثلـة في لإني متوسط الحرارة العظمى والصغرى والرطوبة النسبية وإجمالي معدل سقوط الأمطار على الإنتاج الكلي لمحصول الزيتون

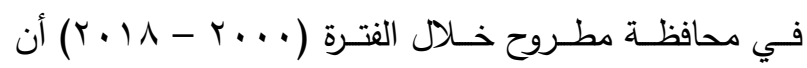

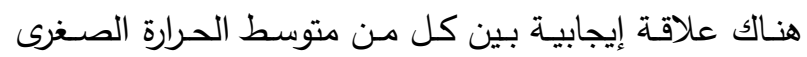
ومتوسط الرطوبة النسبية والإنتاج الكلي لمحصول الزيتون في

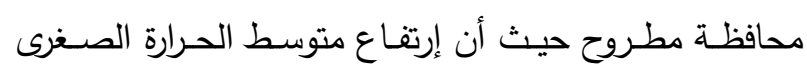

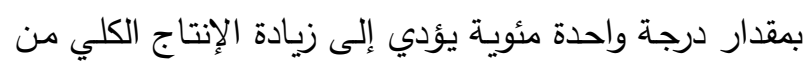

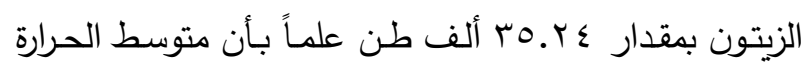

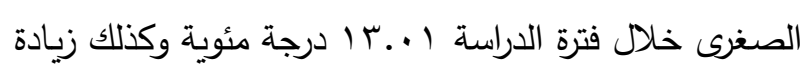
الرطوبـة النسبية بمقدار درجة واحدة يؤدي إلى زيادة الإنتاج

\section{Chart Title}

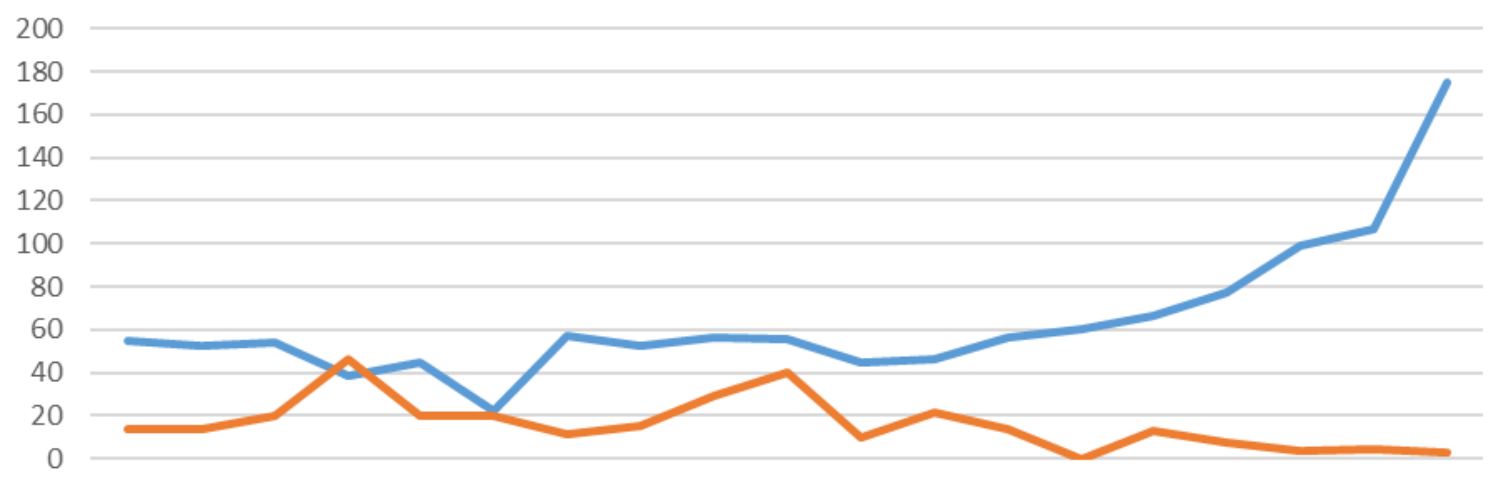

2000200120022003200420052006200720082009201020112012201320142015201620172018 فبر اير سـ الإنتاجس

شكل رقم . إتجاهات معدل سقوط الأمطار لشهر فبراير والإنتاج الكلي لمحصول الزيتون في محافظة مطروح خـلال الفترة $(r \cdot 1 \wedge-r \cdot \cdots)$ المصدر : الجهاز المركزي للتعبئة العامة والإحصاء، النشرة السنوية للجغرافيا والمناخ، أعداد متغرقة. 
بوه رجب إسماعيل مراد،عمرو عبدالحميد رفعت واخرون.: الآثار الاقتصادية للتغيرات المناخية على محصول الزيتون بمحافظة مطروح

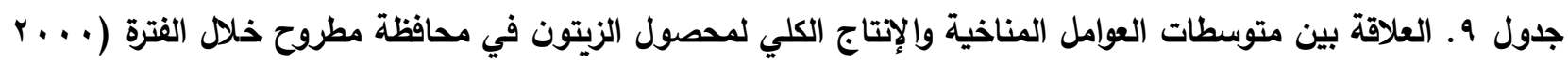

\begin{tabular}{|c|c|c|c|}
\hline ف & j & المعادلة & البيان \\
\hline$\wedge . 乏 0 \wedge$ & $. .01 \leqslant$ & 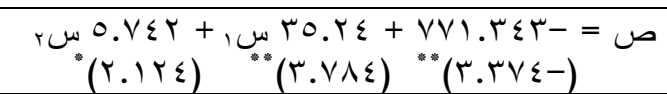 & الزيتون (ألف طن \\
\hline
\end{tabular}

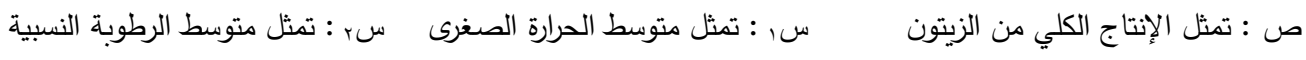

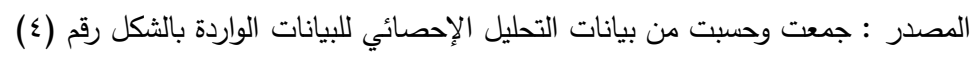

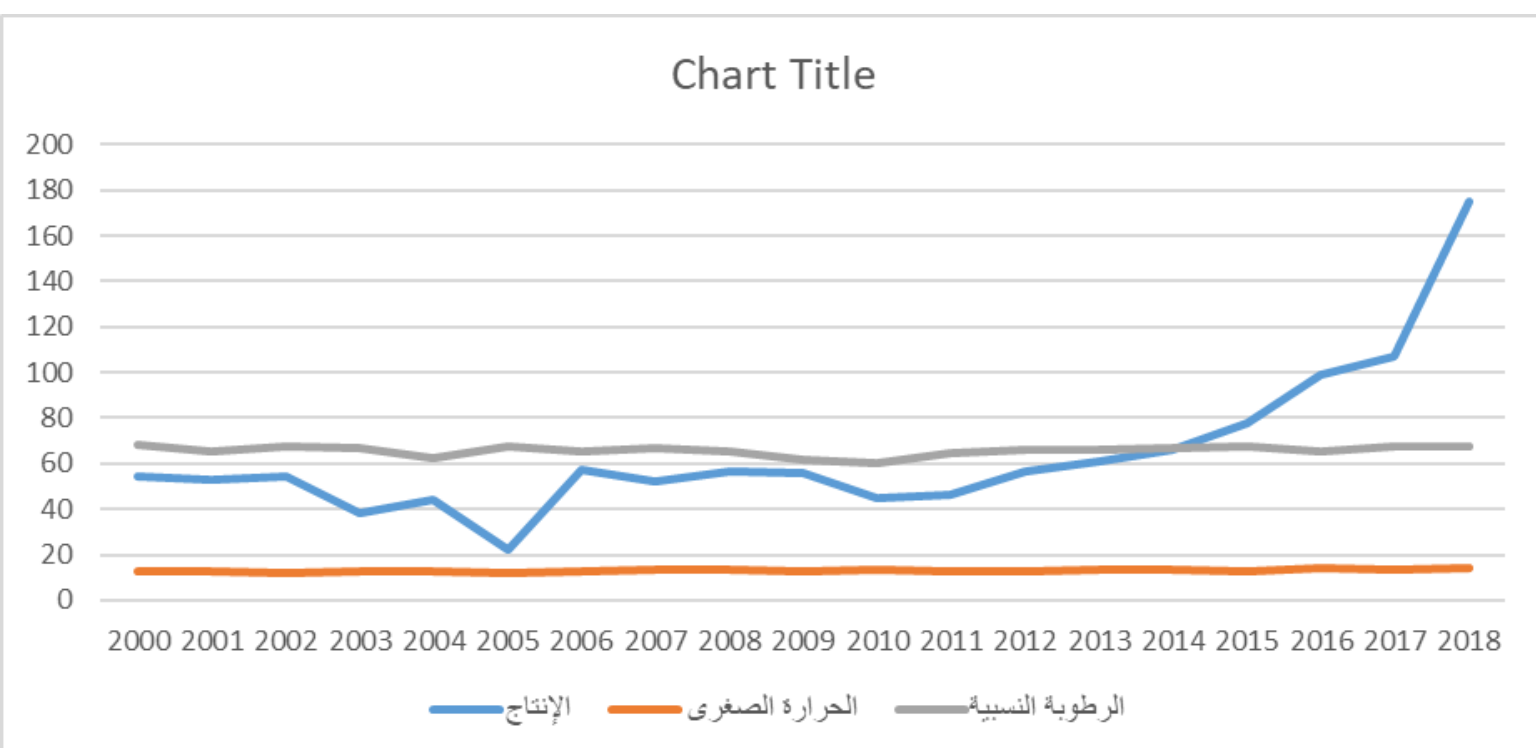

شكل رقم ع . إتجاهات متوسط الحرارة الصغرى ومتوسط الرطوبة النسبية والإتتاج الكلي لمحصول الزيتون في محافظة مطروح

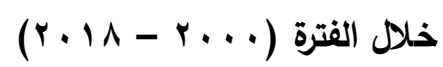

المصدر : الجهاز المركزي للتعبئة العامة والإحصاء، النشرة السنوية للجغرافيا والمناخ، أعداد متفرقة.

المراجح

الجهاز المركزي للتعبئة العامة والإحصاء، النشرة السنوية للجغرافيا والمناخ، أعداد متفرقة. الجهاز المركزي للتعبئة العامة والإحصاء، نشرة تقدير الدخل من

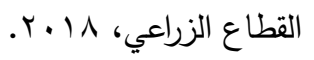

أميـرة محمـــ ربيـع، رقيـة حسـن جبـر ، دراسـة اقتصــادية لإنتـاج

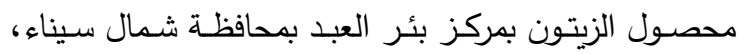

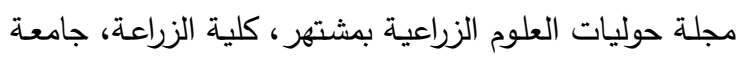

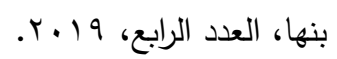

التوصيات:

في ضوء نتائج البحث فإنه يوصي بالآتي:

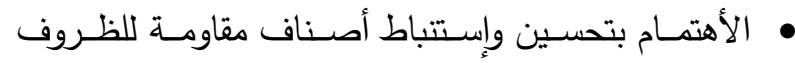
البيئيـة الصـعبة مثل الملوحـة والجفـاف ولهـا قدرة على لهى

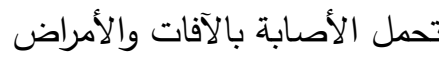

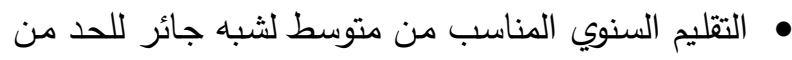
ظاهرة الحمل الخفيف أو الزائد

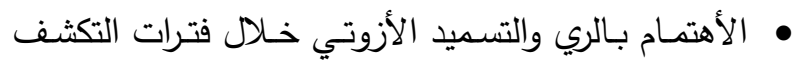
والتحول الزهري من ديسمبر وحتى مارس. 
محمد السيد محمد، إكرام سعد الدين، زراعة وإنتاج الزيتون، معهد

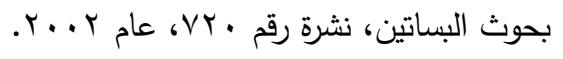

مقدمـة في علوم البيئة، محمد إسـاعيل عمـر، الهيئة المصـرية

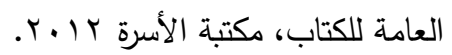

نجوى مسعد العجرودي وآخرون، الآثار المتوقعة للتغيرات المناخية

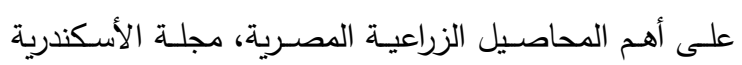

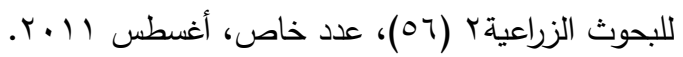

زكي إســاعيل نصـار ، محمــ علي سـكر، الآثـار الإقتصـادية

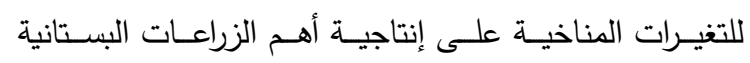

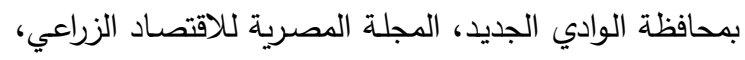

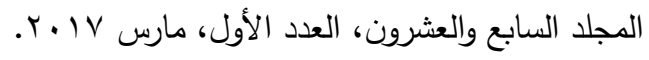
صـلاح أحمد طاحون، التصحر واستعمالات الأراضي في مصر

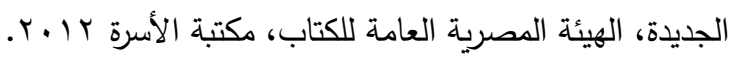
كاظم عبدالوهاب الأسدي زآخرون، أثر التغيرات المناخية العالمية

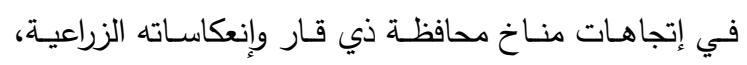

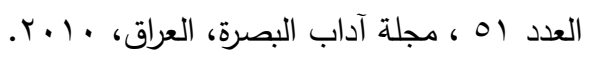


هo9 رجب إسماعيل مراد،عمرو عبدالحميد رفعت واخرون.: الآثار الاقتصادية للتغيرات المناخية على محصول الزيتون بمحافظة مطروح

\title{
ABSTRACT \\ The Economic Effects of Climate Change on the Olive Harvest in Matrouh Governorate
}

\author{
Ragab I. Murad, Amr Abd El-Hameid Refaat, Mohamed Rashad and Ahmed Ayoub Abdelaziz
}

Agricultural production is affected by climatic changes that may affect agricultural production negatively through decreased productivity of some agricultural crops and some positive effects through increasing the productivity of some crops, which calls for studying the economic effects of climate changes to identify the most important climatic factors that affect the production of olive crops in Matrouh Governorate.

The results of the simple regression analysis of the impact of climate change on the total production of the olive crop in Matrouh Governorate during the period $(r \ldots . r \cdot \mid \wedge)$ showed that the increase in the maximum temperature in June by one degree leads to an increase in the total production of the olive crop by $r$, 1 r 9 thousand tons, as it was found. That the rise in the minimum temperature in May by one degree leads to an increase in total production by $r$ r, $V \circ r$ thousand tons, and that an increase in the rate of rainfall in February by one millimetre leads to a decrease in total production by 1, ґ 99 thousand tons.
The results of the statistical assessment of the effect of climatic factors on the total production of the olive crop showed that an increase in the average minimum temperature by one degree leads to an increase in the total production of olives by $r 0, r \leq$ thousand tons as well as an increase in the relative humidity by one degree leading to an increase in the total production of olives in Matrouh governorate Subtracted by $0, \vee \leqslant Y$ thousand tons.

In light of the research results, it recommends the following:

- Taking care to improve and develop varieties that are resistant to difficult environmental conditions such as salinity and drought and have the ability to with stand pests and diseases.

- The appropriate annual pruning from average to semi-invasive to reduce the phenomenon of light or overload.

- Attention to irrigation and nitrogen fertilization during periods of exposure and flowering transformation from December to March. 